\title{
Hypothesis
}

\section{Role of Zinc in Insulin Biosynthesis}

\author{
Some Possible Zinc-Insulin Interactions in the Pancreatic B-cell
}

\author{
S. O. Emdin', G. G. Dodson ${ }^{2}$, J. M. Cutfield ${ }^{3}$, and S. M. Cutfield ${ }^{3}$ \\ ${ }^{1}$ Department of Pathology, University of Umeå, Umeå, Sweden, ${ }^{2}$ Department of Chemistry, University of York, York, England, \\ and ${ }^{3}$ Department of Biochemistry, University of Otago, Dunedin, New Zealand
}

\begin{abstract}
Summary. The behaviour of proinsulin and insulin in the presence of zinc suggests it plays an important role in insulin's production in the B-cell for the vast majority of animal species. The postulate that proinsulin forms a zinc containing hexamer soon after its synthesis and that this organization of the molecule is maintained through all the subsequent processes is supported by our observation that the proinsulin hexamer is converted readily into the insulin hexamer. In addition the zinc ions enhance proinsulin's solubility and render insulin insoluble. Zinc ions also appear to play an important role in the microcrystalline character of the precipitated insulin granule. There may be advantages in condensing the stored material in this way; it will reduce contact with the surrounding membrane where the converting, and possibly other enzymes, are thought to be located, and it will tend to exclude incompletely converted hexamers.
\end{abstract}

Key words: Zinc, insulin, proinsulin, insulin biosynthesis.

It is now relatively clear that insulin is synthesized by means of a series of coordinated events, each of which imposes its own constraints on the hormone's structure [1]. As the molecule moves from one process to the next, different alterations in its structure allow it to satisfy its new environments. Any attempt to understand the molecule's structure and behaviour must take into account these different biosynthetic stages.

Insulin is initially manufactured at the ribosome as a single chain polypeptide of some 110 amino acid residues, pre-proinsulin [1]. It carries a hydrophobic
$\mathrm{N}$-terminal extension of about 25 residues which it has been suggested induces binding of the ribosome to the microsomal membrane [2]. The N-terminal extension is then rapidly removed, giving proinsulin which has the capacity to fold spontaneously into the correct three-dimensional structure [1].

In most species the pancreatic islet B-cell is known to contain high levels of zinc $[3,4]$. Since zinc induces proinsulin hexamerization in vitro [5] it seems likely that proinsulin monomers will aggregate into hexamers in B-cells rich in zinc. There is evidence that the zinc-proinsulin hexamer is closely related to the insulin hexamer and that the insulin moiety in the proinsulin hexamer is organized as the insulin hexamer [5]. While insulin is known to precipitate rapidly at low zinc concentrations, proinsulin remains soluble in the presence of zinc. Hence, proinsulin presumably remains in solution inside the rough endoplasmic reticulum and during the subsequent transport to the Golgi apparatus, where conversion of the substrate to insulin begins [1]. The proteolytic removal of the connecting peptide continues within the storage vesicles [1], which themselves most likely develop from the Golgi apparatus. The newly formed insulin is rapidly precipitated and, in most animals, is frequently observed to assume a crystalline shape [1].

In response to metabolic requirements the vesicle contents are expelled into the circulation, where they bring about the diverse anabolic and regulatory effects of insulin.

The objects of this paper are two-fold: first to describe experiments designed to reveal more about the role of zinc in proinsulin conversion and subsequent granule formation; secondly to discuss how chemical and structural principles, operating in insulin production, explain aspects of insulin's structure. 


\section{Calculations, Experiments and Results}

\section{Zinc and Insulin Levels in the B-cell}

There are a number of reports on the amount of zinc in islet tissue from a variety of species $[3,4,6]$. The zinc levels are usually distributed in two ranges: $2-3 \mathrm{mg} / 100 \mathrm{~g}$ tissue $\left(0.3-0.5 \times 10^{-3} \mathrm{~mol} / \mathrm{l}\right)$ and $10-12 \mathrm{mg} / 100 \mathrm{~g}$ tissue $\left(1.5-1.8 \times 10^{-3} \mathrm{~mol} / \mathrm{l}\right)$. The lower levels are found in animals whose insulins are not crystallized or aggregated to hexamers in the presence of zinc $[7,8]$. The higher concentrations are found in species where the insulins have a specific zinc binding and coordinating capacity [9]. The lower levels of zinc found in islet tissue from guinea pig and the Atlantic hagfish correspond to the levels of zinc found in many other tissues where no particular affinity for zinc has been observed [4]. A similarly low level of zinc (accompanied by a low insulin level) was reported by Berglund and Hellman in severely diabetic mice [10]. On the above basis it seems reasonable to assume that zinc levels of $10 \mathrm{mg} / 100 \mathrm{~g}$ islet tissue is associated with the insulin processing machinery. Given the continuity between the storage vesicle and the cisternal space we will assume a uniform zinc distribution within this compartment, comprising $30 \%$ of the B-cell [11]. Hence, the zinc concentration within the insulin processing compartment can be estimated as $5 \times 10^{-3} \mathrm{~mol} / 1$.

Mammalian islets contain 1-3\% insulin on a wet weight basis (assuming 80\% water content and 75\% B-cells per islet) [12]. About $60-80 \%$ of that insulin is associated with a sedimentable granule fraction [13, $14]$, comprising $12 \%$ of the cell volume [11]. This gives an insulin concentration of $1-3 \times 10^{-2} \mathrm{~mol} / 1$, were it in solution inside the storage vesicle. Similar values can be arrived at by using the number of insulin molecules per granule calculated in three different ways by Howell [15] and the volume of a granule estimated by Lange and Dean [3,11]. Morphometric and chemical analyses show that hagfish insulin is present in its B-cell storage vesicle at about the same level as in other species studied (Emdin, unpublished). At this high concentration insulins are insoluble around neutral $\mathrm{pH}$ and must exist in a crystalline or precipitated state.

The approximately equimolar stoichiometry between zinc and insulin arrived at above, corresponds well with the observation made by Berglund and Hellman [10]. They observed a close correlation between zinc and insulin content in islets from ob/ob mice, and the amounts were roughly equimolar.

Since the biosynthetic process is not in chemical equilibrium we cannot estimate the distribution of zinc between the soluble proinsulin hexamer and the crystalline insulin which both interact with zinc, nor describe the distribution of zinc within the insulin processing machinery. One approach to understand the zinc interactions, which sharpen the discrimination between proinsulin and insulin was to determine the structure of $2 \mathrm{Zn}$ pig insulin crystals soaked in excess zinc ions.

\section{Preparation of the Zinc Soaked Crystals}

Rhombohedral 2 zinc pig insulin crystals (1 $\mathrm{mm}$ in their longest dimension) were crystallized from $0.05 \mathrm{~mol} / 1$ citrate buffer at $\mathrm{pH} 6.2$ following the procedure of Schlichtkrull [19]. The crystals were washed in $2-5 \mathrm{ml} 0.01 \mathrm{~mol} / \mathrm{l}$ acetate $(\mathrm{pH}$ 6.2-7.0) until citrate free. They were then soaked in $1.5 \times 10^{-5}$ $\mathrm{mol} / \mathrm{L}$ zinc sulphate at $\mathrm{pH} 7.0$ for six days. These conditions minimized crystal damage which reduced the quality of X-ray diffraction pattern.

\section{Data Collection}

For X-ray diffraction studies the zinc soaked 2-zinc insulin crystal was mounted in a thin-walled glass capillary with a small reservoir of solution and sealed.

The X-ray diffraction data were collected on an automatic computer controlled Hilger and Watt 4 circle diffractometer. Data were collected out to a spacing of $4.5 \AA$ and corrected for Lorentz, polarization and absorption effects. The agreement factor between equivalents for the 506 independent X-ray reflections, $\mathrm{Rm}$, was 0.047 where:

$$
\mathrm{Rm}=\frac{\sum_{\mathrm{hkl}}\left(\sum_{\mathrm{i}=1}^{\mathrm{n}} I_{\mathrm{i}}-\overline{\mathrm{I}}\right)}{\sum_{\mathrm{hkl}}^{\mathrm{n}} \mathrm{n} \overline{\mathrm{I}}}
$$

( $\mathrm{I}$ is the intensity of the X-ray reflection).

The data were scaled to the native series and correlation made for the larger temperature factor $(\Delta B$ $=14 \AA^{2}$ ) of the zinc soaked crystals.

\section{Determination of the Bound Zinc Positions}

The difference Fourier electron density

$$
\Delta \mathrm{Q}_{\mathrm{xyz}}=\frac{1}{\mathrm{v}} \sum_{\mathrm{h}} \sum_{\mathrm{k}} \sum_{1} \Delta \mathrm{F} \mathrm{e}^{-2 \pi \mathrm{i}(\mathrm{hx}+\mathrm{ky}+\mathrm{lz})}
$$

where $\quad \Delta \mathrm{F}=\mathrm{m}\left(\left|\mathrm{F}_{\mathrm{Zn}}\right|-\left|\mathrm{F}_{\mathrm{nat}}\right|\right) \mathrm{e}^{2 \pi i \alpha_{\mathrm{nks}}}$

and $\quad \mathrm{F}_{\mathrm{Zn}}=$ the structure factor for the zinc soaked crystal structure

$\mathrm{F}_{\text {nat }}=$ the structure factor for the native crystal 
was calculated using phases $\alpha_{\mathrm{hkl}}$ determined by isomorphous replacement [16]. The figure of merit, which is a measure of the phases' quality, is denoted by $\mathbf{m}$.

There were two prominent peaks in the map. Their positions and occupancies were refined by least squares, minimizing:

$\mathrm{E}^{2}=\Sigma \mathrm{w}\left(\mathrm{K}\left|\mathrm{F}_{\mathrm{Zn}}\right|-\left|\mathrm{F}_{\mathrm{nat}}+\mathrm{f}_{\mathrm{Zn}}\right|\right)$

where $\mathrm{K}=$ the scale to native and zinc soaked series, $\mathrm{W}=$ the weighting term: in this case the figure of merit for the isomorphous phase.

The figure of merit was cut off in these calculations at 0.85 reducing the number of terms to 433 .

A subsequent difference Fourier was calculated in which the electron density

$\Delta \varrho=\frac{1}{\mathrm{~V}} \sum_{\mathrm{hkl}} \Delta \mathrm{F} \mathrm{e}^{-2 \pi \mathrm{i}(\mathrm{hx}+\mathrm{ky}+\mathrm{lz})}$

where

$\left.\Delta \mathbf{F}=\mathbf{m}\left(\mid F_{Z n}\right]-\left|F_{n a t}+f_{Z n}\right|\right) e^{2 \pi i \alpha_{\text {hke }}}$

and $\mathrm{f}_{\mathrm{Zn}}=$ the calculated zinc ion contribution to $\mathrm{F}_{\mathrm{Zn}}$. This showed further peaks of lower occupancy. Zinc ions were placed at the positions of the peaks and were subjected to least squares refinement. Those zinc positions which refined to an occupancy greater than $7 \overline{\mathrm{e}}$ are listed in Table 1 . The nearest residue to each zinc position is also listed.

The agreement factor

$\mathrm{R}=\frac{\sum_{\mathrm{hkl}}\left(\left|\mathrm{F}_{\mathrm{Zn}}\right|-\left|\mathrm{F}_{\text {nat }}+\mathrm{f}_{\mathrm{Zn}}\right|\right)}{\sum_{\text {hkl }}\left|\mathrm{F}_{\mathrm{Zn}}\right|}$

fell from $19.0 \%$, assuming no zinc binding, to $14.4 \%$ when the bound zinc ions were included.

\section{The Bound Zinc Positions}

Distinction between the centrally coordinated zinc ions, which bind to histidyl side chains and organize the hexamer, and those which bind less specifically to carboxylate groups has to be made. We do this by referring to the former as coordinated and the latter as bound zinc. Depending on the insulin's conformation and the condition in the vesicle, there would be between 2 and 4 zinc ions coordinated per hexamer corresponding to the known 2 and $4 \mathrm{Zn}$ insulin crystals. The two central zinc ions coordinated to the $\mathrm{B}_{10}$ histidines in $2 \mathrm{Zn}$ insulin are not affected by the presence of the additional zinc ions and there is no evidence for the development of extra zinc coordination by $\mathrm{B}_{5}$ histidine as seen for example in $4 \mathrm{Zn}$ insulin
Table 1. Details of zinc coordination and binding in $2 \mathrm{Zn}$ pig insulin crystals

\begin{tabular}{|c|c|c|c|c|c|}
\hline \multirow{2}{*}{$\begin{array}{l}\text { Site } \\
\text { number }\end{array}$} & \multicolumn{3}{|c|}{ Coordinates } & \multirow{2}{*}{$\begin{array}{l}\text { Occu- } \\
\text { pancy }\end{array}$} & \multirow[t]{2}{*}{ Nearest residue } \\
\hline & $\mathrm{x}$ & $\mathrm{y}$ & $\mathrm{z}$ & & \\
\hline 1 & 0.0 & 0.0 & 0.23 & 1.00 & $\mathrm{~B}_{10}$ (I) histidine \\
\hline 2 & 0.0 & 0.0 & -0.24 & 1.00 & $\mathrm{~B}_{10}$ (II) histidine \\
\hline 3 & 0.03 & 0.02 & 0.01 & 0.80 & $\mathrm{~B}_{13}(\mathrm{I}+\mathrm{II})$ glutamic acid \\
\hline 4 & 0.13 & 0.30 & 0.57 & 0.67 & $\begin{array}{l}\mathrm{B}_{30} \text { (II) carboxylic acid } \\
\mathrm{A}_{4} \text { (II) glutamic acid }\end{array}$ \\
\hline 5 & 0.10 & 0.10 & 0.51 & 0.37 & $\mathrm{~B}_{5}(\mathrm{I}+\mathrm{II})$ histidine \\
\hline 6 & 0.33 & 0.14 & 0.98 & 0.38 & $\mathrm{~A}_{17}$ glutamic acid \\
\hline 7 & 0.29 & 0.17 & 0.09 & 0.38 & $\begin{array}{l}\mathrm{A}_{17} \text { (I) glutamic acid } \\
\mathrm{B}_{1} \text { (II) } \propto \text {-amino }\end{array}$ \\
\hline 8 & 0.11 & 0.07 & 0.37 & 0.33 & $\mathrm{~B}_{5}(\mathrm{I})$ histidine \\
\hline 9 & 0.18 & 0.27 & 0.27 & 0.27 & $\mathrm{~B}_{21}$ (II) glutamic acid \\
\hline
\end{tabular}

The I and II refer to the two independent molecules in the $2 \mathrm{Zn}$ pig insulin crystal asymmetric unit

The zinc positions are in fractional coordinates referred to hexagonal axes

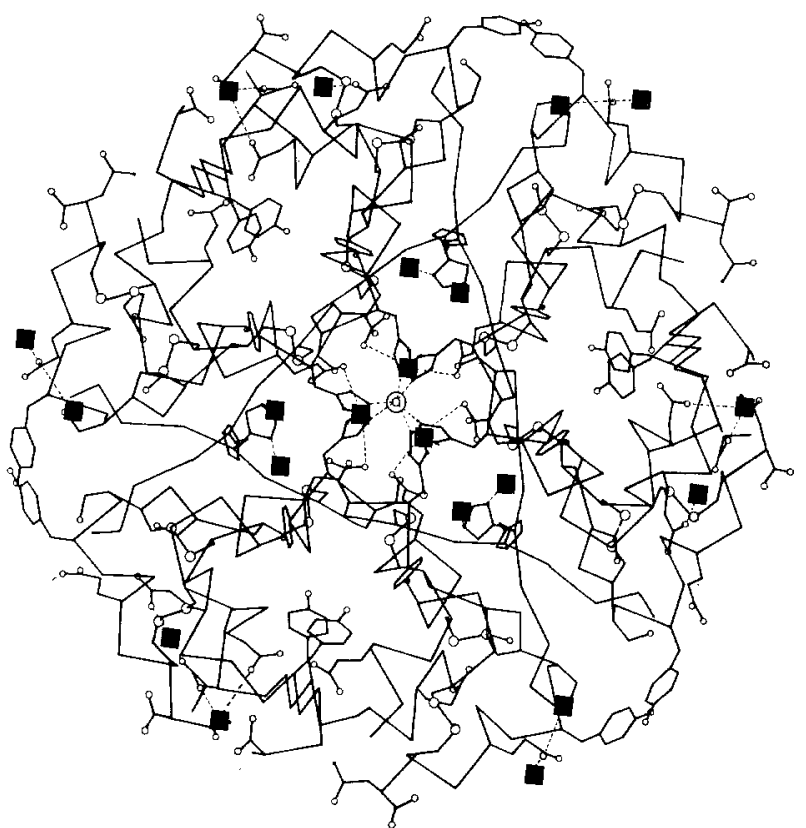

Fig. 1. The $2 \mathrm{Zn}$ pig insulin hexamer viewed down the three fold crystal axis. The main chain structure is represented by the $\alpha$ carbon positions only. The tyrosine sidechains, which make contact in dimer and hexamer formation are shown, as well as the histidine sidechains. Sidechains which are interacting with zinc ions are connected by dots to the bound zinc ions represented as squares

[17]. The most fully occupied new site is at the hexamer centre between the two $B_{13}$ glutamic acid sidechains paired together by the association of insulin dimers in the hexamer (Fig. 1). At lower pH (6.0 6.5) divalent metal ion binding still occurs at this site but is reduced at the other sites (Dodson, unpublished). It seems likely that substitution at $B_{13}$ sidechains can occur when the hexamers is in solution. 


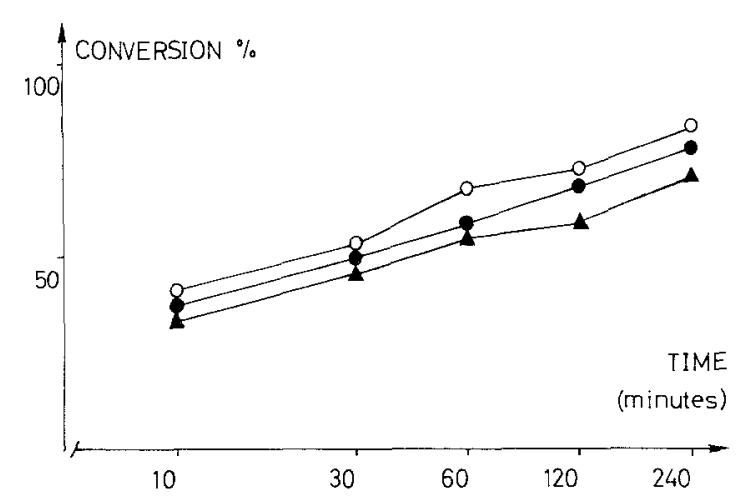

Fig. 2. Time course of proinsulin conversion with and without zinc. Pig proinsulin $\left(0.8 \times 10^{-3} \mathrm{~mol} / \mathrm{l}\right)$ was incubated with trypsin $(1: 300)$ at $\mathrm{pH} 7.3,37^{\circ} \mathrm{C}$ for the times indicated. The rate of conversion was analyzed by gel electrophoresis and calculated as described in the text. Conditions were: $(O)$ with $0.5 \times 10^{-3} \mathrm{~mol} / \mathrm{l}$ EDTA, (•) with two zine ions per proinsulin hexamer and $(\boldsymbol{\Delta})$ with six zinc ions per hexamer

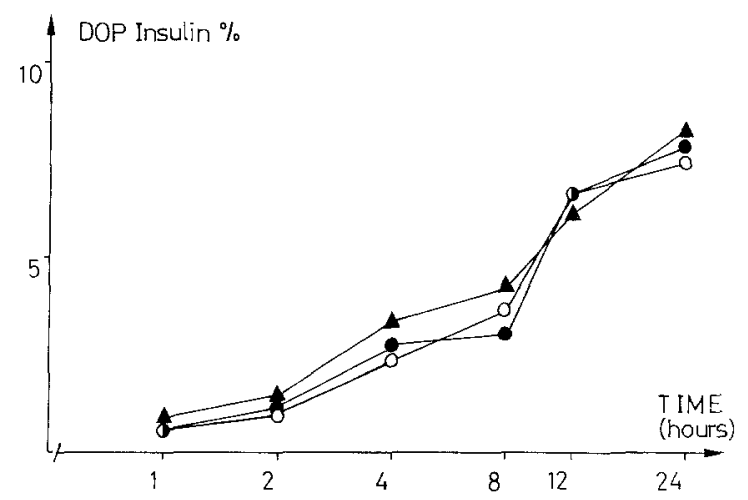

Fig. 3. Time course of desoctapeptide (DOP) - insulin formation with and without zinc. Pig insulin $\left(0.5 \times 10^{-3} \mathrm{~mol} / 1\right)$ was incubated with trypsin $(1: 100)$ at $\mathrm{pH} 7.3,37^{\circ} \mathrm{C}$. The rate of DOP-insulin formation was calculated after gel electrophoresis (see text). Conditions were: (O) with $0.5 \times 10^{-3} \mathrm{~mol} / 1 \mathrm{EDTA},(\bullet)$ with two zinc ions per insulin hexamer and $(\boldsymbol{A})$ with six zinc ions per insulin hexamer

Binding at the three symmetry related sites at $\mathrm{B}_{13}$, together with the two centrally coordinated zincs, gives in total about five zincs per hexamer.

The additional zinc binding in the 2-zinc insulin crystal takes place on the hexamer's surface and involves interactions with mostly glutamic acid and histidine sidechains. The position of these sites and their adjacent side chains are illustrated in Figure 1; altogether there are seven zinc binding sites and two to four coordination sites per hexamer. Some of these zinc binding sites are produced by crystal packing and would probably not occur in solution. There is a total amount of 11.6 zinc ions in the hexamer; this corresponds to about $2.3 \%$. This figure is sensibly near $2.5 \%$, which is the value reported by
Schlichtkrull for the zinc content in rhombohedral insulin crystal preparations in acetate buffer at neutral $\mathrm{pH}[18]$.

\section{Effect of Zinc on Tryptic Proinsulin Conversion}

Pig proinsulin, with a zinc content of $0.02 \%$ was dissolved in $0.05 \mathrm{~mol} / 1 \mathrm{Tris}-\mathrm{HCl} \mathrm{pH} 7.3$ to a concentration of $0.8 \times 10^{-3} \mathrm{~mol} / \mathrm{l}$. The proinsulin was incubated at $37^{\circ} \mathrm{C}$ with trypsin (diphenyl-carbamyl-chloridetreated, Sigma) $1: 300(\mathrm{w} / \mathrm{w})$ and either EDTA $0.5 \times 10^{-3} \mathrm{~mol} / 1$ or zinc acetate yielding two or six zinc ions per proinsulin hexamer. At intervals samples were withdrawn and combined with an excess of soybean trypsin inhibitor (Sigma). The samples were analyzed by gel electrophoresis at $\mathrm{pH} 8.7$ [19]. The protein bands were stained with Coomassie Brilliant Blue [20] and quantitated with a gel scanner. The amount of proinsulin converted was calculated as the sum of the optical densities of des $\mathrm{B}_{30}$-insulin and the intermediate(s) moving to a position in between proinsulin and insulin [21], divided by the sum of proinsulin, des $\mathrm{B}_{30}$-insulin and intermediate(s). During the course of the reaction a precipitate (diarginyl-insulin) formed after about four minutes both with and without zinc. The time-course of the reaction is shown in Figure 2. At the most, a slight reduction of the conversion-rate in the presence of zinc was noted. In similar experiments with potassium phosphate buffer $(0.1 \mathrm{~mol} / 1, \mathrm{pH} 7.5)$ this difference of rates was even further reduced. Hence, the overall time course of tryptic proinsulin conversion was not significantly perturbed by the presence of zinc and the different aggregation state induced by the cation.

\section{Effect of Zinc on Tryptic Insulin Degradation}

Trypsin induced insulin degradation was studied by measuring the rate of desoctapeptide (DOP) insulin formation. Pig insulin with a zinc content of $0.02 \%$ and at a concentration of $0.5 \times 10^{-3} \mathrm{~mol} / \mathrm{l}$ was incubated with trypsin $(1: 100 \mathrm{w} / \mathrm{w})$ under conditions otherwise similar to above. After gel electrophoresis and optical scanning, the amount of DOP-insulin formed was calculated as; DOP insulin: (DOP insulin + insulin). The over-all time course of this reaction is shown in Figure 3. When zinc was added to a level of six zinc ions per hexamer insulin precipitated instantaneously, but the rate of DOP-insulin formation was not affected. As with proinsulin, experiments were also performed in phosphate buffer at $\mathrm{pH} 7.5$ but we found no difference with or without zinc. Hence, insulin degradation by trypsin was neither affected by the different states studied here, dimeric and hexameric, nor the precipitation of the substrate with equimolar amounts of zinc ions. 


\section{Calcium and Zinc as Insulin Precipitating Agents}

Based on experiments with islets cultured in calciumfree medium, Howell et al. suggested that this cation may have an important function in insulin storage [22]. Calcium is known to precipitate insulin, and to bind to rhombohedral zinc insulin crystals (Blundell, Bedarkar, private communication; Dodson, unpublished). There is also the evidence that calcium is present in the secretion granules [15]. In an attempt to compare the abilities of zinc and calcium to precipitate insulin the simple experiment presented in Table 2 was done. It showed that zinc was far more able than calcium to precipitate insulin. This difference, more than one order of magnitude, was most pronounced at low insulin concentrations.

\section{Discussion}

Generally accepted functions for zinc in the production of insulin by the zinc-rich B-cell are:

1. Assembly of the proinsulin and the derived insulin hexamers $[5,9]$.

\section{Solubility of the zinc proinsulin hexamer [5].}

3. Precipitation and crystallization of the nascent insulin $[5,9]$.

4. Crystal formation which presumably reduces the rate of proteolysis, especially by the converting enzyme(s) $[9,23]$.

It is clear from this list that zinc ions play a central role in insulin biosynthesis. Since there is now considerable experimental evidence that the hexameric structure has the right properties for the chemical and structural events that take place at each stage after the folding of the proinsulin monomer, we shall assume the hexameric organization is preserved intact throughout the processing after the initial biosynthetic steps.

\section{Assembly, Solubility and Zinc Binding of Proinsulin}

As soon as a sufficient number of proinsulin molecules inside the rough endoplasmic reticulum are released from their $\mathrm{N}$-terminal extensions they will, after folding, presumably assemble into hexamers in which two or four zinc ions are centrally coordinated provided enough zinc is present [17]. Proinsulin is a remarkably soluble molecule. Grant et al. have shown that proinsulin in vitro is organized as a zinc hexamer with aggregation properties closely
Table 2. Calcium and zinc as insulin precipitating agents

\begin{tabular}{rll}
\hline $\begin{array}{l}\text { Pig insulin } \\
\text { concentrations mol/1 }\end{array}$ & \multicolumn{2}{l}{$\begin{array}{l}\text { Number of cations/insulin monomer } \\
\text { giving precipitation }\end{array}$} \\
\cline { 2 - 3 } & Calcium & Zinc \\
\hline $5 \cdot 10^{-6}$ & No ppt $^{\mathrm{a}}$ & No ppt \\
$25 \cdot 10^{-6}$ & No ppt $^{\mathrm{a}}$ & 1.4 \\
$50 \cdot 10^{-6}$ & No ppt & 1 \\
$250 \cdot 10^{-6}$ & No $\mathrm{ppt}^{\mathrm{a}}$ & 1 \\
$330 \cdot 10^{-6}$ & 440 & 1 \\
$500 \cdot 10^{-6}$ & 74 & 1 \\
\hline
\end{tabular}

${ }^{\mathrm{a}} \mathrm{ppt}=$ precipitate

Small volumes of concentrated solutions of either $\mathrm{CaCl}_{2}$ or $\mathrm{ZnCl}_{2}$ were added to a series of insulin solutions $(0.05 \mathrm{~mol} / 1 \mathrm{Tris}-\mathrm{HCl}, \mathrm{pH}$ 7.3 at $37^{\circ} \mathrm{C}$ ) ranging in concentration from 5 to $500 \times 10^{-6} \mathrm{~mol} / 1$. This was repeated every five minutes until precipitation or turbidity appeared. In cases where no precipitation was seen the $\mathrm{CaCl}_{2}$ and $\mathrm{ZnCl}_{2}$ solutions were added until they were at $1 \mathrm{~mol} / 1$ concentration $1 \mathrm{mmol} / 1$ concentration respectively

similar to those of insulin [5]. The pig proinsulin hexamer, which at neutral $\mathrm{pH}$ carries a net charge of -12 , has a capacity to bind 30 zinc ions per hexamer, of which two to four are coordinated. Proinsulin's solubility as a hexamer is thus enhanced by the addition of 60 positive charges, present as a coat of zinc ions, roughly equivalent to the 54 negatively charged groups on the surface of the pig proinsulin hexamer [5].

The zinc binding sites in rhombohedral $2 \mathrm{Zn}$ pig insulin are usually found adjacent to carboxylate groups. The dispersal of these sites on the molecule's surface is expected but their fractional occupancy suggests they do not and cannot assume the appropriate geometry for favourable coordination. There is, however, one highly occupied site at the hexamer's centre between the two $B_{13}$ glutamic acid side chains brought together by the molecule's assembly. Here the double zinc charges are balanced completely by the two carboxylate groups (Fig. 1).

This pattern of high occupancy being associated with the pairing of the negatively charged carboxylate groups suggests an explanation for the zinc binding capacities of proinsulin. There are 54 carboxylate groups in the pig proinsulin hexamer and as the hexamer binds some 30 zinc ions in vitro then it is likely they are all involved in interaction with the cation. We propose this stoichiometry in the zinc binding might be achieved through pairing of the carboxylic acid side chains, brought about by the folding of the connecting peptide and the slight restructuring in the insulin moiety. Among the zinc-binding insulins the near invariance of four glutamic acid residues and of the aspartic acid residue in the connecting peptide sequence is consistent with them having such a 
specific structural role on the surface. Snell and Smyth have attempted to predict the folding of the proinsulin connecting peptide [24]. There is no pairing of carboxylate groups in their proposed structure.

High solubility in the cell will presumably be achieved by the process of zinc binding, facilitating the transport of the prohormone to its site of conversion. In this organized state the proinsulin has buried all the residues thought to be involved in the expression of the biological activity, either by aggregation or by folding of the connecting peptide [10]. Whether the burial of these residues is a necessary biological device we do not know.

\section{Conversion of Proinsulin}

Kemmler et al. have shown that under strictly controlled conditions a mixture of trypsin and carboxypeptidase B will convert zinc-free bovine proinsulin to native insulin [25]. We suggest that upon arrival at the Golgi apparatus some five to ten minutes later, the prohormone, still organized as a hexamer, is converted to an insulin hexamer by the enzyme(s) with tryptic and carboxypeptidase-B-like specificity [1]. We would expect this from proinsulin's behaviour in solution and from the observation that conversion with trypsin in vitro is virtually unaffected by the presence of zinc (i. e. hexameric conformation). We can understand the equal ability of the zinc proinsulin hexamer and zinc-free proinsulin to be converted by reference to the $2 \mathrm{Zn}$ pig insulin hexamer structure. Here we find the exposure of the B-chain's C-terminus and the A-chain's $\mathrm{N}$-terminus unaffected by the assembly to dimers and hexamers [16].

With the removal of the 6 connecting peptides, possibly completed in one exposure to the enzyme, the pig proinsulin hexamer loses 24 carboxylic acid side groups. We propose that the loss of these charges and the structural changes at the A-chain N-terminus and B-chain C-terminus drastically reduces the molecule's capacity to bind zinc. Grant et al. [5] report that insulin's solubility falls sharply as the bound zinc increases from 3-6 zinc ions per hexamer. We note that 6 zinc ions will exactly neutralize the net 12 negative charges present and favour precipitation; perhaps this favourable stoichiometry explains the role zinc plays in the insulin hexamer's lower solubility. Moreover, the loss of the 24 negative charges with the removal of the C-peptide and the 24 basic connecting residues (4 per monomer) and the exposure of 12 benzene rings ( $A_{19}$ tyrosines and $B_{25}$ phenylalanines) may further reduce solubility by increasing the non-polar surface of the hexamer.

The insolubility of the converted product will favour complete hydrolysis of the soluble precursor.
A certain fraction of proinsulin monomers (about $2-4 \%$ ) remain unconverted in the hexamer and are incorporated into the crystal and expelled into the circulation [26], which may be seen as an unfavourable consequence of the insulin hexamer's insolubility.

Finally we have shown that calcium compared with zinc, is a poor insulin precipitating agent and we consider that the initial precipitation of the newly converted insulin is induced by zinc not by calcium and occurs at insulin concentrations several orders of magnitude below insulin's point of saturation.

\section{Crystallization within the Storage Vesicle}

In animals whose insulins are coordinated by zinc examination of electron micrographs reveals crystalline granules in the B-cells [27]. The abundance of such apparently crystalline structures may vary with fixation and the species under study and they may be scarce within the B-cell. Lange, who has studied this problem in detail, has interpreted crystallization in B-granules as being accidental rather than essential [29]. The constitution of the stored insulin crystals has only be examined directly in the grass snake and the salamander using optical transforms [29]. In these two animals the crystals are not rhombohedral. Comparable studies have not been reported on insulins whose crystals have been characterized in vitro, such as that of the rat and pig. Two crystalline forms of the rat insulins have been obtained in the laboratory, one rhombohedral and the other cubic. These have been related to the two characteristic crystalline forms observed in the granules in the rat pancreatic B-cell [20]. Some variation in the insulin storage crystal in the presence of the other numerous molecular species, such as calcium ions, arginine, lysine and the connecting peptide present in the storage granule, is perhaps to be expected. Supporting this is the observation that in the laboratory with pig and beef insulin we find the crystal form and the conditions of precipitation can easily be changed by adding various molecules to the solution (Cutfield, Dodson, Tolley, unpublished, [18]).

Schlichtkrull [18] has shown that insulin precipitates as microcrystals in the presence of zinc ions between $\mathrm{pH} 4.8-5.6$. In the B-cell storage vesicle the picture is complicated. The presence of other molecules in the vesicle is also likely to alter the $\mathrm{pH}$ range of the phenomenon. Insulin's high concentration in the vesicle may itself buffer the $\mathrm{pH}$ to nearer 6. These factors may explain Lange's observation that no in vivo insulin crystal corresponds to any known crystal form grown in the laboratory [29]. 


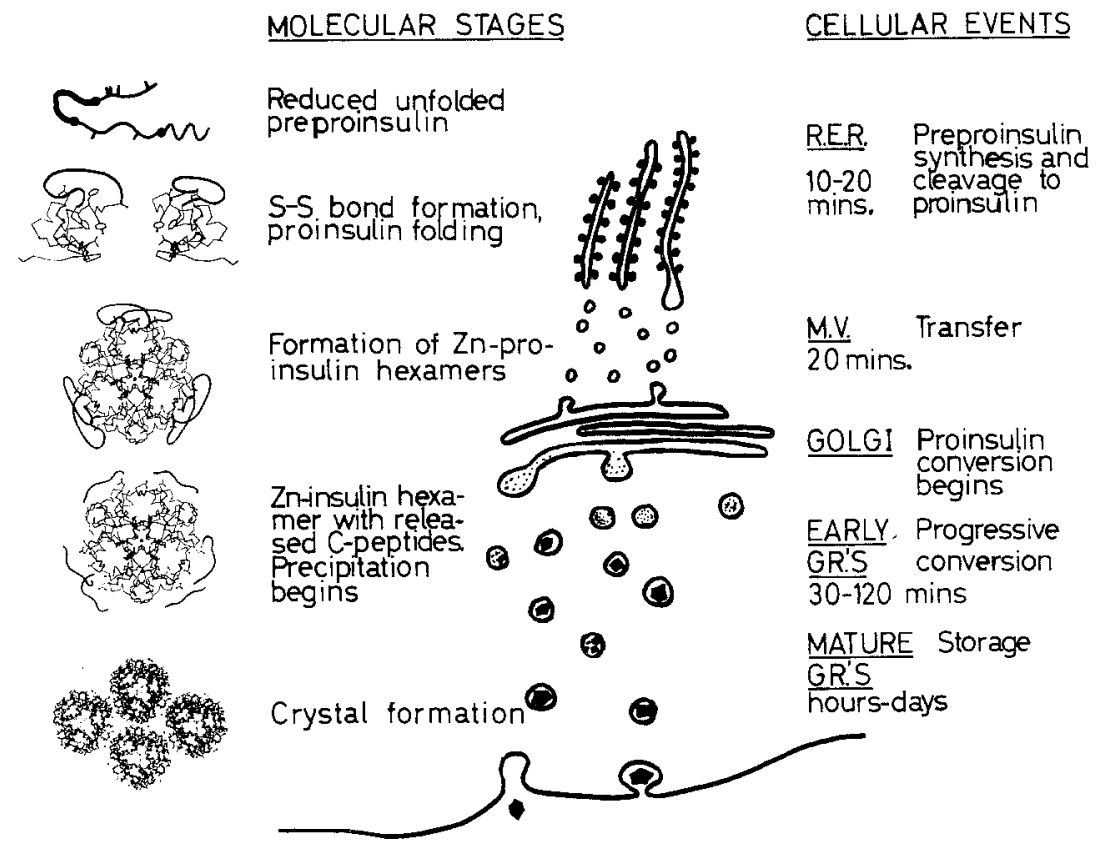

Fig. 4. Schematic drawing of the elements in the B-cell responsible for insulin biosynthesis. Alongside this scheme are the corresponding molecular species present at the different stages of insulin's biosynthesis. (Partly redrawn from Steiner et al. [34])
Crystallisation of the converted hexamer may help ensure high conversion in the insulin hexamer since the crystal packing requirements will effectively exclude proinsulin surfaces from being incorporated into the crystal. In support of this Steiner [31] has demonstrated that proinsulin inhibits the growth of insulin crystals, though it must be borne in mind this experiment was done at low zinc and insulin concentrations.

Discussion of what role insulin's crystallisation plays in preventing proteolysis during storage is limited by our ignorance of the converting enzyme's specificity. Experiments with trypsin, which is specific for basic residues, suggest there are advantages in dimerisation [32]. A pancreatic protease isolated by Yip was able to cleave the $B_{22}-B_{23}$ bond only in the absence of zinc; clearly the hexameric structure protected the hormone from attack by this enzyme [33]. We find that hexameric insulin in solution, or in the precipitated state, is as labile to trypsin as the dimer. This observation is consistent with the idea that crystallisation does provide protection to the stored insulin from an enzyme with trypsin like properties simply by condensing the molecules into crystals.

\section{Zinc-free Insulins}

In considering the role of zinc in the insulin processing machinery it is interesting to compare, where possible, the biosynthetic events in B-cells with high and low levels of zinc. An important difference is the appearance of the insulin storage vesicle. In zinc-rich
B-cells the granules characteristically appear crystalline while in B-cells [27] with low levels of zinc the stored insulin is dispersed more uniformly throughout the vesicles. In the hagfish B-cell the granules are never condensed $[28,35]$, whereas in the guinea pig a minority of the granules are condensed, but they do not appear crystalline (Howell, personal communication). Loading of the proinsulin hexamer with zinc ions appears an important factor in its solubility. It is a question whether hagfish and guinea pig proinsulins can and need to bind zinc in their cellular environment where the zinc levels are significantly lower. The distribution of carboxylic acid chains in guinea pig proinsulin differs somewhat from the other proinsulins [24], and there is in addition evidence of structural alterations in the guinea pig insulin moiety [36]. These differences may be sufficient to abolish its zinc binding capacity but consideration of the sequence does suggest guinea pig proinsulin might bind zinc ions. Similar speculations about the hagfish proinsulin cannot be made since its structure is not known. If these two proinsulins cannot bind sufficient zinc then their solubilities must be determined solely by the character of their surface residues, as must be also the solubilities of the newly produced insulin, which will be precipitated only when the concentration builds up to high enough levels. This lag between the appearance of insulin and its precipitation is in sharp contrast to the rapid zinc-induced crystalline precipitation on the zinc-rich B-cell.

It is interesting to note that the amount of zinc required for insulin production is very small in relation to the total zinc content of the body. By proces- 
sing its insulin at low levels of zinc, rather than at high levels, a guinea pig saves only some $0.1 \%$ of its total zinc content. One possible explanation for the lack of condensed crystalline granules in non zinc binding insulin storage vesicles is that these insulins are very resistant to further cleavage by their converting enzyme(s). The loss of zinc in the guinea pig and coypu insulin producing machinery is not then a consequence of a zinc shortage [23] but follows the ability of the insulin to dispense with aggregation in storage. This, in turn, removes the structural constraints on the residues responsible for assembly [9, 23], and the zinc ions, no longer necessary, are lost.

\section{Effects during and after Secretion}

There remain further possible roles for zinc ions in the events that take place during and after insulin's secretion. It has been established that insulin crystals and granules become more stable in the presence of surplus zinc ions $[15,18,37]$. It is hard to estimate the speed with which the zinc ions in the crystal will disperse as the vesicle contents are expelled via the basal membranes into the circulating medium; but while they are present the zinc ions will affect the crystal's rate of dissolution.

The balance of the evidence suggests that the insulin molecule moves into the blood as a hexamer and, we may speculate, with a local packet of liberated zinc ions. The observation that zinc ions affect insulin's binding and degradation in the liver [38] suggests a further possible role for zinc ions outside the $\mathrm{B}$-cell. If this is a function for zinc then one might expect differences in the insulin binding and degradation properties of guinea pig and hagfish livers since in these animals the B cell does not have high levels of zinc ions.

\section{Conclusion}

The biological processes that occur during insulin's production are reflected in the sequences, structures and chemical behaviour of proinsulin and insulin. An interesting feature in the biosynthesis of insulin is the role of the zinc ion whose chemical properties are incorporated into the whole process. This is illustrated schematically in Figure 4. The zinc ions are not, however, essential - several animals produce insulin without using zinc ions. Their incorporation, however, amplifies with great advantage the chemistry available to the proinsulin and insulin molecules, particularly in their aggregation and solubility properties.
There are still gaps in our knowledge; the converting enzyme(s) has not yet been characterized and we do not know enough about what other proteins and enzymes are present in the vesicle membrane. As these details become known we will be in a better position to understand not only insulin's structure, but also the structural differences in insulins from different animal species.

Acknowledgements. Supported by grants from The British Medical Research Council and the Swedish Medical Research Council $(12 X-718)$, and the British and Swedish Diabetes Associations. Some of the zinc binding studies were carried out in the Laboratory of Molecular Biophysics at Oxford University. We are grateful for the help and interest of Professor Dorothy Hodgkin and David Phillips.

\section{References}

1. Steiner DF (1976) Insulin today. Diabetes 26: 322-340

2. Blobel G, Sabatine DD (1971) Ribosome-membrane interaction in eukaryotic cells. Biomembranes 2: 193-195

3. Lange RH (1973) Histochemistry of the islets of Langerhans. In: Graumann W, Neumann $K$ (eds) Handbuch der Histochemie. Gustav Fischer Stuttgart, Bd VIII/I, pp 1-269

4. Havu N, Lundgren G, Falkmer S (1977) Zinc and manganese contents of micro-dissected pancreatic islets of some rodents. Acta Endocrinol (Kbh) 86: 570-577

5. Grant PT, Coombs TL, Frank BH (1972) Differences in the nature of the interactions of insulin and proinsulin with zinc. Biochem J 126: 433-440

6. Havu N, Lundgren G, Falkmer S (1977) Microchemical assays of glutathione, zinc, cobalt and manganese in micro-dissected areas of the endocrine pancreas in the hagfish, Myxine glutinosa. Acta Endocrinol (Kbh) 86: 561--569

7. Peterson JD, Coulter CL, Steiner DF, Emdin SO, Falkmer S (1974) Structural and crystallographic observations on hagfish insulin. Nature 251: 239-240

8. Zimmerman AE, Yip CC (1974) Guinea pig insulin. J Biol Chem 249: 4021-4025

9. Blundell T, Dodson G, Hodgkin D, Mercola D (1972) Insulin: The structure in the crystal and its reflection in chemistry and biology. Adv Protein Chem 26: 279-402

10. Berglund O, Hellman B (1976) Evidence for a role of zinc in the storage of insulin in the mouse pancreatic B-cells. Diabetologia 12: 380-381

11. Dean PM (1973) Ultrastructural morphometry of the pancreatic $\beta$ cell. Diabetologia 9: 115-119

12. Hellman B, Täljedal I-B (1972) Histochemistry of the pancreatic islet cells. In: Steiner DF, Freinkel N (eds) Handbook of physiology, endocrinology 1 . Williams and Wilkins, Baltimore, p 91-110

13. Howell SL, Fink CJ, Lacy PE (1969) Isolation and properties of secretory granules from rat islets of Langerhans. J Cell Biol 41: 154-161

14. Noe BD, Baste CA, Bauer GE (1977) Studies on proinsulin and proglucagon biosynthesis and conversion at the subcellular level. J Cell Biol 74: 578-588

15. Howell SL (1974) The molecular organization of the $\beta$ granule of the islets of Langerhans Adv Cytopharmacol 2: 319-327

16. Adams MJ, Blundell TL, Dodson EJ, Dodson GG, Vijayan M, Baker EN, Harding MM, Hodgkin DC, Rimmer B, Sheat $S$ (1969) Structure of rhombohedral 2 Zinc insulin crystals. Nature 224: 491-495 
17. Bentley G, Dodson E, Dodson G, Hodgkin D, Mercola D (1976) Structure of insulin in 4-zinc insulin. Nature 261: 166-168

18. Schlichtkrull J (1961) Insulin crystals. Thesis Univ, of Copenhagen

19. Ornstein L, Davies JB (1962) Disc electrophoresis. Distillation Products Industries, Rochester, New York

20. Diezel W, Kopperschläger G, Hofmann E (1972) An improved procedure for protein staining in polyacrylamide gels with a new type of Coomassie Brilliant Blue. Anal Biochem 48: $617-620$

21. Steiner DF, Clark JL, Nolan C, Rubinstein AH, Margoliash E, Aten B, Oyer PE (1969) Proinsulin and the biosynthesis of insulin. Recent Prog Horm Res 25: 207-282

22. Howell SL, Tyhurst M, Duvefelt H, Andersson A, Hellerström C (1978) Role of zinc and calcium in the formation and storage of insulin in the pancreatic $\beta$ cell. Cell Tissue Res 188: $107-118$

23. Blundell TL, Wood SP (1975) Is the evolution of insulin Darwinian or due to selectively natural mutation? Nature 257: 197-203

24. Snell CR, Smyth DG (1975) Proinsulin: A proposed threedimensional structure. J Biol Chem 250: 6291-6295

25. Kemmler W, Peterson JD, Steiner DF (1971) Studies on the conversion of proinsulin to insulin. $J$ Biol Chem 246: 6786-6791

26. Steiner DF, Kemmler W, Clark J, Oyer PE, Rubinstein AH (1972) The biosynthesis of insulin. In: Steiner DF, Freinkel N (eds) Handbook of physiology, endocrinology 1 . Williams and Wilkins, Baltimore, p 175-198

27. Sato T, Herman L, Fitzgeraid PJ (1966) The comparative ultrastructure of the pancreatic islet of Langerhans. Gen Comp Endocrinol 7: 132-157

28. Östberg Y (1976) The entero-insular endocrine organ in a cyclostome Myxine glutinosa. Thesis. Umeå Univ. Med. Diss. New Ser. No. 15

29. Lange RH (1976) Crystallography of islet secretory granules a contribution to the problem of chemical composition of sec- retion granules. In: Fujita $\mathrm{T}$ (ed) Endocrine gut and pancreas. Elsevier Scientific Publishing Co, Amsterdam, p 167-178

30. Wood SD, Tickle IJ, Blundell TL, Wollmer A, Steiner DF (1978) Insulin polymorphism: Physical and biological proper ties of rat insulins. Arch Biochem Biophys 186: 175-183

31. Steiner DF (1973) Cocrystallisation of proinsulin and insulin. Nature 243: 528-530

32. Wang S-S Carpenter FH (1969) Kinetics of the tryptic hydrolysis of zinc-free bovine insulin. J Biol Chem 244: 5537-5543 (1969)

33. Yip CC (1971) A bovine pancreatic enzyme catalyzing the conversion of proinsulin to insulin. Proc Natl Acad Sci USA 68: $1312-315$

34. Steiner DF, Kemmler W, Tager, HS, Rubinstein AH, Lernmark $\AA$, Zühlke $H$ (1975) Proteolytic mechanisms in the biosynthesis of polypeptide hormones. In: Reich E, Rifkin DB, Shaw E (eds) Proteases and biological control. Cold Spring Harbor Laboratory, p 531-549

35. Emdin SO, Falkmer S (1977) Phylogeny of insulin. Acta Paediatr Scand [Suppl] 270: 15-25

36. Massey DE, Smyth DG (1975) Guinea pig proinsulin. J Biol Chem 250: 6288-6290

37. Coore HG, Hellman B, Pihl E, Täljedahl I-B (1970) In: Falkmer S, Hellman B, Tähjedahl I-B (eds): The structure and metabolism of the pancreatic islets. Pergamon Press, Oxford, p 385-395

38. Arquilla ER, Packer S, Tarmas W, Miaymoto S (1978) The effect of zinc on insulin metabolism. Endocrinology 103: 1440-1449

Received: September 18, 1979, and in revised form: April 25, 1980

\section{G. G. Dodson}

Chemistry Department

York University

York, Y01 5DD

England 